\title{
Multidisciplinary approach of non-responders after bariatric surgery reduces the indication for revisional surgery: a retrospective cohort study
}

Marleen Romeijn ( $\square$ Marleen.Romeijn@mmc.nl )

Maxima Medisch Centrum https://orcid.org/0000-0001-6582-5255

Martine Uittenbogaart

Maxima Medisch Centrum

François M. $\mathrm{H}$. van Dielen

Maxima Medisch Centrum

Arijan A. P. M. Luijten

Maxima Medisch Centrum

Loes Janssen

Maxima Medisch Centrum

Wouter K. G. Leclercq

Maxima Medisch Centrum

Research article

Keywords: bariatric surgery, non-response, weight regain, multidisciplinary team, revisional surgery

Posted Date: August 3rd, 2020

DOI: https://doi.org/10.21203/rs.3.rs-48047/v1

License: (1) This work is licensed under a Creative Commons Attribution 4.0 International License.

Read Full License 


\section{Abstract \\ Background}

$20-30 \%$ of patients show a lack of response after bariatric surgery (BS). These non-responders may experience insufficient weight loss or significant weight regain. Based on previous research in our center, it has been identified that before the introduction of a multidisciplinary team (MDT), $68 \%$ of the nonresponders underwent revisional surgery. This study describes the effect of an MDT on treatment strategy in non-responders after BS.

\section{Methods}

this retrospective study included non-responders that were reviewed in an MDT meeting. Patients were categorized as primary non- responders (1NR) or as secondary non-responders (2NR). Outcomes assessed were: I. MDT-based treatment (conservative versus operative), II. Weight loss, III. Complications after revisional surgery.

\section{Results}

a total of 104 patients were included ( $n=151 \mathrm{NR}, \mathrm{n}=89$ 2NR). In 73 patients, lifestyle and/or behavioral changes were indicated. Only eleven patients $(13 \%)$ were re-operated in which one complication occurred. Twenty patients did not show up at their appointment with the dietician, physical therapist and/or medical psychologist and were excluded from further analysis. Conservatively treated patients lost $2.1 \mathrm{~kg}$ $<12$ months $(S D=7.29)$ and $0.8 \mathrm{~kg}<24$ months $(S D=5.08)$. Surgically treated patients lost $12.0 \mathrm{~kg}<12$ months $(S D=4.29)$ and $26.3 \mathrm{~kg}<24$ months $(S D=2.75)$.

\section{Conclusions}

the rate of revisional surgery decreased after the introduction of an MDT. An explanation for this could be that an MDT drives more patients towards a conservative treatment since it identifies modifiable lifestyle and/or behavioral factors contributing to non-response. Incorporation of an MDT may contribute to the selection of patients who might benefit from revisional surgery.

\section{Background}

Bariatric surgery (BS) has proven to be the most effective treatment for obesity in achieving long-term weight maintenance [1-2]. Unfortunately, $20-30 \%$ of patients do not respond well after BS as they experience insufficient weight loss or significant weight regain [3-4]. Popular criteria for describing insufficient weight loss are $<50 \%$ excess weight loss (EWL), or $<20 \%$ total weight loss (TWL) $1-2$ years after surgery [5]. Hereafter, insufficient weight loss is described as primary non-response (1NR) while 
regaining an excessive amount of weight, after initial successful weight loss, is described as secondary non-response (2NR) [6]. The etiology for non-response can be lifestyle related but can also be found in anatomical alterations like a dilated pouch or gastroenterostomy, or gastro-gastric fistula [7-8].

Revisional BS constitutes a popular solution for non-responders. Commonly offered revisional procedures are Roux-en-Y gastric bypass (RYGB), lengthening of biliopancreatic limb, band placement, revision of the gastric pouch and/or stoma or biliopancreatic diversion/ duodenal switch (BPD/DS) [7-9]. Up to now, the efficacy and safety of these procedures remain controversial as each procedure brings along specific risks [10]. Lengthening of the biliopancreatic limb may result in severe malnutrition leading to the need for reoperations. Band placement may result in reoperation due to dysphagia and/or band migration. Revision of the pouch and/or stoma displayed unsatisfactory results with no BMI loss comparing the prerevision and 2-year post-revision situation [11].

In 1991, the National Institutes of Health Consensus Statement advocated that a multidisciplinary team (MDT) is required to optimize bariatric patient care [12]. This resulted in the formation of dedicated teams consisting of bariatric surgeons, obesity physicians, dieticians, physical therapists and medical psychologists. The beneficial effect of MDTs on surgical outcome has extensively been described in surgical oncology [13-15]. However, the effect of an MDT in non-responders after BS is relatively poorly understood. It was Srivastava et al. who demonstrated that a multidisciplinary lifestyle intervention combined with medication could improve early weight loss in non-responders [16].

Based on previous research in our center between 2012 and 2015, it has been identified that before the introduction of an MDT, $68 \%$ of the non-responders underwent revisional surgery [9]. This study included 65 patients with weight loss failure and weight regain who were consulted by a bariatric surgeon, though consultation by a dietician and physical therapist and/or medical psychologist was not scheduled routinely. Furthermore, no joint meeting by the MDT took place. It is likely that the role of an MDT needs further expansion in the management of non-responders after BS. The aim of this study was to describe the effect of an MDT, in a bariatric tertiary referral center, on treatment strategy in non-responders after BS.

\section{Methods}

Study population

Data about non-responders was collected in our center from January 2016 till December 2018 and was retrospectively analyzed. Patients were included if they regained $>5 \%$ weight with respect to the lowest postoperative weight after RYGB or sleeve gastrectomy (SG) (nadir weight). At the moment of inclusion, > $5 \%$ regain was a commonly used cut-off point [6]. Patients with a previous history of BS such as laparoscopic adjustable gastric banding or Mason gastroplasty were included as well. Patients were excluded in case of a banded gastric bypass, one anastomosis gastric bypass (OAGB) or BPD. The primary BS could have taken place in our center or elsewhere. In our center, all patients were screened for primary BS by an MDT. On top of the regular treatment, a preoperative individual treatment was given if 
indicated by the MDT. Patients were categorized as primary non-response (1NR) if the patients' excess weight loss (EWL) was less than 50\% 12-24 months after primary surgery; patients were categorized as secondary non-response (2NR) if the EWL exceeded the 50\% EWL threshold and a regain of $>5 \%$ was reported (nadir weight). All patients were discussed in an MDT meeting. The below section describes in more detail the process and approach taken before and during the MDT assessment.

Assessment before MDT meeting

Initial assessment of the patient was done by the bariatric surgeon. Hereafter, the patient was referred to the dietician and physical therapist for assessment of nutritional habits and physical activity. The dietician focused on food intake, food choices, satiety, hunger and signs of emotional eating; the physical therapist focused on an activity habits. If indicated, consultation of a medical psychologist was offered. Gastrointestinal contrast studies and laboratory tests were only performed on indication.

MDT meeting

Once the patient had a consultation with all members of the team individually, the treatment strategy was discussed in a joint MDT meeting (weekly occurrence). These meetings included at least one member of the following fields of expertise: bariatric surgeon, nurse practitioner, dietician, physical therapist and medical psychologist; the meeting was chaired by an experienced bariatric surgeon. Notably, under certain circumstances the patient was discussed in the MDT despite that he/she was not seen by all members of the team. For example, in case of persistent lack of attendance at one of the appointments.

\section{MDT treatment strategy}

After evaluation of the patient by the team, a decision was taken whether the patient needed further lifestyle and/or behavioral intervention, or whether the patient was qualified for revisional surgery. On behalf of this study, treatment options were divided into conservative and operative treatment (Fig. 1). A conservative treatment consisted of a nutritional and/or physical intervention, summarized as "lifestyle". A nutritional intervention was indicated, for example, in case of unhealthy food choices and detrimental eating patterns. A physical intervention was indicated in case of a sedentary lifestyle with the goal to increase activity habits. A behavioral intervention was indicated when there were signs of emotional eating and problems in impulse control. If there were signs indicating an eating disorder, patients were referred to a psychiatric clinic specialized in treatment of such disorders. The indication for operative treatment was not based on the degree of non-response. The type of procedure depended on the index procedure, perioperative findings and expert opinion.

\section{Study outcomes}

Patient demographics evaluated in this study include gender, age, BMI, weight loss, previous surgical history and relevant comorbidities. Outcome parameters were MDT-based treatment categorized as conservative or operative, weight loss in a period of 24 months after MDT meeting and complications after revisional surgery. Weight loss was described as \%EWL and was calculated as follows: (initial 
weight - final weight) / (initial weight - ideal body weight) $\times 100 \%$. Ideal body weight is based on a BMI of $25 \mathrm{~kg} / \mathrm{m}^{2}$. Initial body weight was the weight at the moment of screening. Optional, weight loss was also expressed in percent total weight loss (\%TWL). \%TWL was calculated as follows: ((preoperative weight final weight) / preoperative weight) $) \times 100 \%$. The percent of regain was calculated as percent $\mathrm{kg}$ gained after reaching lowest postoperative weight.

Statistical Analyses

Descriptive statistics were computed for demographic and medical characteristics. Quantitative data are presented as mean with standard deviation or median with interquartile range; categorical data are expressed in percentages. A paired t-test was performed for comparing pre- and posttreatment weight.

\section{Results}

Description of the population

A total of 119 non-responders were assessed of which fifteen patients were excluded for having a banded gastric bypass, OAGB, gastric band or BPD. Therefore, 104 patients were included in the study. The group of 1 NR consisted of 15 patients and the group of 2NR consisted of 89 patients (Table 1). In the group of 2NR, 19 patients received an individual treatment, while in the group of 1NR none of the patients received an individual treatment. Moreover, $40 \%$ of the patients with 1 NR had a history of gastric banding, while only $16 \%$ had this history in the group of 2 NR. 
Table 1

Baseline characteristics of the study population

\begin{tabular}{|c|c|c|c|}
\hline & Total $n=104$ & $1 \mathrm{NR} n=15$ & $2 N R n=89$ \\
\hline Gender, no. (\%) & $92(88.5)$ & $11(73.3)$ & $81(91.0)$ \\
\hline Female & $12(11.5)$ & $4(26.7)$ & $8(9.0)$ \\
\hline \multicolumn{4}{|l|}{ Male } \\
\hline Age $^{\#}(\text { years })^{1}$ & $44.2 \pm 9.8(27-69)$ & $44.4 \pm 10.6(23-69)$ & $44.2 \pm 9.7(27-66)$ \\
\hline \multirow{2}{*}{$\begin{array}{l}\text { Preoperative comorbidities, no. } \\
(\%)\end{array}$} & $20(19.2)$ & $2(13.3)$ & $18(20.0)$ \\
\hline & $9(8.7)$ & - & $9(10.1)$ \\
\hline $\begin{array}{l}\text { Hypertension } \\
\text { Type II diabetes }\end{array}$ & $5(4.8)$ & $1(6.7)$ & $4(4.5)$ \\
\hline & $10(9.6)$ & $2(13.3)$ & $8(9.0)$ \\
\hline Dyslipidaemia & $7(6.7)$ & - & $7(7.9)$ \\
\hline \multicolumn{4}{|l|}{ Osteoarthritis } \\
\hline Comorbidities, no. (\%) & $18(17.3)$ & $1(6.7)$ & $17(19.1)$ \\
\hline Unchanged & $19(18.3)$ & $1(6.7)$ & $18(20.2)$ \\
\hline Disappeared & $4(3.8)$ & $1(6.7)$ & $3(3.4)$ \\
\hline \multicolumn{4}{|l|}{ Recurrence } \\
\hline $\begin{array}{l}\text { Preoperative individual treatment, } \\
\text { no. }(\%)\end{array}$ & 19 (18.3) & - & $19(21.3)$ \\
\hline History of bariatric surgery, no. (\%) & $20(19.2)$ & $6(40.0)$ & $14(15.7)$ \\
\hline LAGB & $6(5.8)$ & $2(13.3)$ & $4(4.5)$ \\
\hline Mason & $6(5.8)$ & $4(26.7)$ & $2(2.2)$ \\
\hline SG & & & \\
\hline
\end{tabular}

\footnotetext{
\# Age at time of MDT meeting

${ }^{1}$ Expressed in mean \pm SD (range): ${ }^{2}$ Expressed in median (IQR 25-75)

List of abbreviations: MDT = Multidisciplinary Team, OSAS = Obstructive Sleep Apnoea Syndrome, $\mathrm{BMI}=$ Body Mass Index, LAGB = Laparoscopic Adjustable Gastric Banding, RYGB = Roux-en-Y Gastric bypass, $\mathrm{SG}=$ Sleeve Gastrectomy, EWL = Excess Weight Loss, TWL = Total Weight Loss, $\mathrm{SD}=$ Standard Deviation, IQR = Interquartile Range.

Data presented as number (\%), mean (standard deviation) or median (interquartile range)
} 


\begin{tabular}{|c|c|c|c|}
\hline & Total $n=104$ & $1 N R n=15$ & 2NR $n=89$ \\
\hline Type of surgery, no. (\%) & $93(89.4)$ & $14(93.3)$ & 79 (88.8) \\
\hline RYGB & $11(10.6)$ & $1(6.7)$ & $10(11.2)$ \\
\hline SG & $99(95.2)$ & $14(93.3)$ & $85(95.5)$ \\
\hline Laparoscopic & $5(4.8)$ & $1(6.7)$ & $4(4.5)$ \\
\hline \multicolumn{4}{|l|}{ Laparotomy } \\
\hline Complications, no. (\%) & $92(88.5)$ & $15(100.0)$ & $77(86.5)$ \\
\hline No complications & $2(1.9)$ & - & $2(2.2)$ \\
\hline Clavien-Dindo grade I & $3(2.9)$ & - & $3(3.4)$ \\
\hline Clavien-Dindo grade II & $7(6.7)$ & - & $7(7.9)$ \\
\hline \multicolumn{4}{|l|}{ Clavien-Dindo grade III } \\
\hline Interval to presentation (years) ${ }^{2}$ & $4(3-6)$ & $5(3-7)$ & $4(3-5)$ \\
\hline Preoperative weight $(\mathrm{kg})^{1}$ & $\begin{array}{l}130.9 \pm 23.5(94- \\
231)\end{array}$ & $\begin{array}{l}135.8 \pm 29.7(102- \\
188)\end{array}$ & $\begin{array}{l}130.1 \pm 22.4(94- \\
231)\end{array}$ \\
\hline Preoperative BMI $\left(\mathrm{kg} / \mathrm{m}^{2}\right)^{2}$ & $43.6(40.8-48.4)$ & $47.4(36.2-53.5)$ & $43.5(41.1-47.9)$ \\
\hline Maximal EWL (\%) ${ }^{1}$ & $\begin{array}{l}75.9 \pm 24.3(9- \\
127)\end{array}$ & $37.7 \pm 10.8(9-48)$ & $\begin{array}{l}82.4 \pm 19.4(50- \\
127)\end{array}$ \\
\hline Maximal TWL $(\%)^{1}$ & $32.6 \pm 10.1(3-52)$ & $16.6 \pm 6.6(3-27)$ & $35.3 \pm 7.9(19-52)$ \\
\hline Weight regain $(\%)^{2}$ & $20.3(14.1-30.9)$ & $12.4(8.0-18.0)$ & $22.7(14.9-32.1)$ \\
\hline \multicolumn{4}{|l|}{ \# Age at time of MDT meeting } \\
\hline \multicolumn{4}{|c|}{${ }^{1}$ Expressed in mean \pm SD (range): ${ }^{2}$ Expressed in median (IQR 25-75) } \\
\hline \multicolumn{4}{|c|}{$\begin{array}{l}\text { List of abbreviations: MDT = Multidisciplinary Team, OSAS = Obstructive Sleep Apnoea Syndrome, } \\
\text { BMI = Body Mass Index, LAGB = Laparoscopic Adjustable Gastric Banding, RYGB = Roux-en-Y Gastric } \\
\text { bypass, SG = Sleeve Gastrectomy, EWL = Excess Weight Loss, TWL = Total Weight Loss, SD = } \\
\text { Standard Deviation, IQR = Interquartile Range. }\end{array}$} \\
\hline
\end{tabular}

Description of MDT-based treatment

Prior to MDT meeting, $98 \%$ was referred to a dietician, $97 \%$ was referred to a physical therapist and $28 \%$ was referred to a medical psychologist (Table 2; Fig. 2). Twenty patients did not show up at the appointment with the dietician and/or physical therapist and/or medical psychologist. Therefore, no optimal treatment could be advised and consequently these patients were excluded from further analysis. 
In total, $87 \%$ received a conservative treatment and $13 \%$ an operative treatment. When focusing on the conservative treatment, $86 \%$ received a nutritional intervention, $63 \%$ received a physical intervention and $25 \%$ received a behavioral intervention.

Table 2

Overview of MDT-based treatment in non-responders

\begin{tabular}{|llll|}
\hline & Total $\mathbf{n}=104$ & 1NR $\mathbf{n = 1 5}$ & 2NR $\mathbf{n = 8 9}$ \\
\hline Referred patients & $102(98.1)$ & $15(100.0)$ & $87(97.8)$ \\
Dietician & $101(97.1)$ & $15(100.0)$ & $86(96.6)$ \\
Physical therapist & $29(27.9)$ & $6(40.0)$ & $23(25.8)$ \\
Medical psychologist & & & \\
\hline No show & $20(19.2)$ & $3(20.0)$ & $17(19.1)$ \\
\hline Subtotal $\mathbf{n}=\mathbf{8 4}$ & $1 \mathrm{NR} \mathbf{n = 1 2}$ & $\mathbf{2 N R} \mathbf{n = 7 2}$ \\
\hline Alternation of the limb length & 11 & - & 11 \\
Revision of the gastric pouch and/or stoma & $7(63.6)$ & - & $3(27.3)$ \\
RYGB & $2(18.2)$ & - & $2(63.6)$ \\
Ring placement & $1(9.1)$ & - & $1(9.1)$ \\
\hline Conservative treatment, no. & 73 & 12 & 61 \\
Nutritional intervention & $63(86.3)$ & $53(86.9)$ & $10(83.3)$ \\
Physical intervention & $46(63.0)$ & $39(63.9)$ & $7(58.3)$ \\
Behavioral intervention & $18(24.7)$ & $14(23.0)$ & $4(33.3)$ \\
Referred to psychiatric institution & $4(5.5)$ & $2(3.3)$ & $2(16.7)$ \\
\hline Data presented as number (\%) & & & \\
\hline
\end{tabular}

Effect of MDT-based treatment on weight loss outcomes

Table 3 displays the effect on weight loss within 12 months and 24 months after start of the treatment. As a result of conservative treatment, patients with $1 \mathrm{NR}$ lost $1.2 \mathrm{~kg}$ within 12 months (SD = 4.3) and $2.8 \mathrm{~kg}$ within 24 months $(S D=2.7)$. Patients with $2 \mathrm{NR}$ lost $2.4 \mathrm{~kg}$ within 12 months $(S D=7.8)$ and $0.4 \mathrm{~kg}$ within 24 months $(S D=5.4)$. These results did not reach significance compared to their baseline weight. Additional analysis showed that within the group of conservatively treated patients with 2 NR $49 \%$ did not gain any more weight or lost weight, while $51 \%$ gained weight within 24 months. The results of the surgically treated patients with $2 \mathrm{NR}$ are more pronounced. On average, these patients lost $12.0 \mathrm{~kg}$ within 
12 months $(S D=10.8)$ and $26.3 \mathrm{~kg}$ within 24 months $(S D=1.1)$. The weight loss within 12 and 24 months was statistically significant $(p<0.05)$.

Table 3

Effect of MDT-based treatment on weight loss outcomes in non-responders

\begin{tabular}{|c|c|c|c|c|c|c|c|}
\hline & \multirow[t]{2}{*}{$\begin{array}{l}\text { Weight at start of treatment } \\
(\mathrm{kg}) \text { mean, } \pm S D\end{array}$} & \multicolumn{3}{|c|}{$\Delta$ Weight $\leq 12$ months } & \multicolumn{3}{|c|}{$\begin{array}{l}\Delta \text { Weight } \leq 24 \\
\text { months }\end{array}$} \\
\hline & & $\mathbf{n}$ & $\begin{array}{l}\text { mean } \\
\mathrm{kg} \pm \mathrm{SD}\end{array}$ & value & $\mathbf{N}$ & $\begin{array}{l}\text { mean } \\
\mathrm{kg} \pm \\
\mathrm{SD}\end{array}$ & $\begin{array}{l}\mathrm{p} \\
\text { value }\end{array}$ \\
\hline \multirow{2}{*}{$\begin{array}{l}\text { Conservative } \\
\text { treatment }\end{array}$} & $106.2 \pm 21.5$ & 42 & \multirow{2}{*}{$\begin{array}{l}-2.1 \pm \\
7.3\end{array}$} & .06 & 17 & \multirow{2}{*}{$\begin{array}{l}-0.8 \\
\pm 5.1\end{array}$} & .49 \\
\hline & $128.7 \pm 25.0$ & 7 & & .48 & 3 & & .21 \\
\hline \multirow{2}{*}{$\begin{array}{l}\text { Total } \\
\text { Primary non- } \\
\text { response (1NR) }\end{array}$} & \multirow[t]{3}{*}{$101.9 \pm 17.9$} & \multirow[t]{3}{*}{35} & $\begin{array}{l}-1.2 \pm \\
4.3\end{array}$ & .08 & 14 & $\begin{array}{l}-2.8 \\
\pm 2.7\end{array}$ & .77 \\
\hline & & & \multirow[t]{2}{*}{$\begin{array}{l}-2.4 \pm \\
7.8\end{array}$} & & & \multirow[t]{2}{*}{$\begin{array}{l}-0.4 \\
\pm 5.4\end{array}$} & \\
\hline \multicolumn{4}{|l|}{$\begin{array}{l}\text { Secondary non- } \\
\text { response (2NR) }\end{array}$} & & & & \\
\hline Surgical treatment & \multirow[t]{2}{*}{$115.6 \pm 17.9$} & \multirow[t]{2}{*}{9} & \multirow[t]{2}{*}{$\begin{array}{l}-12.0 \\
\pm 10.8\end{array}$} & $.01 *$ & 2 & \multirow{2}{*}{$\begin{array}{l}- \\
26.3 \\
\pm 1.1\end{array}$} & \multirow[t]{2}{*}{$.02 *$} \\
\hline $\begin{array}{l}\text { Secondary non- } \\
\text { response (2NR) }\end{array}$ & & & & & & & \\
\hline
\end{tabular}

The results were recalculated in \%TWL. When using $\geq 15 \%$ TWL as a cut-off point for successful weight loss, six patients were categorized as $1 \mathrm{NR}$ and 98 patients as $2 \mathrm{NR}$. This gives an enlargement of the group of the 2NR without affecting weight loss outcomes (conservatively treated patients lost $-2.4 \mathrm{~kg}<$ 12 months $S D=7.6$ and $-1.7 \mathrm{~kg}<24$ months $S D=5.4$, data not shown).

Effect of MDT-based operative treatment on surgical outcomes

Eleven patients were selected for operative treatment since no major nutritional-, physical-, or behavioral changes were identified. These re-operated patients were all categorized as $2 \mathrm{NR}$. The index procedure was RYGB in 9 patients and SG in 2 patients. Four different surgical procedures were performed in these patients which are described in Table 2. In detail, 2 patients with prior SG underwent conversion to RYGB; 3 patients with perioperative common limb lengths between $440-600 \mathrm{~cm}$ underwent shortening of this common limb; 7 patients with a perioperative large pouch and/or stoma underwent resizing; 1 patient additionally received a gastric ring. Postoperative, one complication occurred in a patient with a history of gastric banding, followed by RYGB and subsequent alteration of the limb length. This patient developed, one year after alteration, an ulcerative stenosis at the gastroenterostomy treated with endoscopic dilatation. 


\section{Discussion}

There is no standardized approach in the treatment of non-responders following bariatric surgery. While ongoing studies about the efficacy of revisional surgery are being reported in literature, studies about the effect of a multidisciplinary approach fall behind. To our knowledge, this report is first in describing an MDT approach for non-responders after BS. The most interesting finding is that the minority of patients (13\%) underwent revisional surgery, while all other patients (87\%) were considered as not eligible for surgery. Before the introduction of an MDT evaluation in our center, the rate of revisional surgery was much higher (68\% versus $13 \%$ ) [9]. Based on these findings, it is likely to assume that an MDT approach reduced the indication for revisional surgery. An explanation for this is that an MDT approach elicits important lifestyle and/or behavioral factors driving patients towards a conservative treatment.

When reviewing weight loss outcomes, revisional surgery was most effective in managing non-response. The nine re-operated patients achieved a weight loss of $12.0 \mathrm{~kg}(\mathrm{SD}=10.8)$, recalculated as $35.9 \% \mathrm{EWL}$ $(S D=36.2)$ and $29 \%$ TWL (SD = 5.2) 24 months after surgery. This result differs from the weight loss that was found earlier in forty re-operated patients lacking an MDT approach (17.6\% EWL, SD = 28.3) [9]. This difference suggests that weight loss outcomes of surgically treated non-responders have been improved due to the introduction of an MDT. One can argue that an MDT approach gives a more accurate way of selecting candidates for revisional surgery. This should however be interpreted with caution since the cohort of re-operated patients in this study was very small, different surgical procedures were performed by different surgeons leading to performance bias and the results showed high variation in weight loss outcomes.

It is noteworthy to mention that the $50 \%$ of conservatively treated patients did not gain weight and the other $50 \%$ only gained minor percentages. Therefore, the question is raised why should we offer evaluation by an MDT. Perhaps, the MDT underselected appropriate candidates for revisional surgery. Although it is difficult to conclude on this based on this study, it could be presumed that an MDT is helpful in identifying lifestyle and behavioral factors contributing to non-response. When ignoring these factors while performing surgery, patients may be at risk for surgical morbidities. For further practices, a checklist of lifestyle and behavioral factors was made when evaluating candidates for revisional surgery (Table 4). 
Table 4

Checklist of factors that can be used during assessment of a patient with non-response advocating conservative and surgical treatment

\section{Factors in favor of conservative treatment \\ Factors in favor of surgical treatment}

Excessive dietary intake

Inappropriate food choices

Lack of satiety

Constant hunger sensation

Emotional eating

Binge eating

Sweet eating

Grazing behavior

Physically inactive

Mental health disorder, e.g., depression,

anxiety, personality disorders

Alcohol or drug use
Signs of surgical failure, e.g., pouch or stoma dilatation, gastrogastric fistula

Dietary compliance

No signs of maladaptive eating habits

Physically active

No signs of mental health disorder

No signs of alcohol or drug use

The observed complication rate within this study is in line with other literature. Complication rate after pouch/anastomosis revision is estimated at 3.5\% and after limb alteration 12\% [10]. Revision of the gastric pouch and/or stoma was most frequently performed in this study. None of the seven patients that underwent this procedure suffered from a complication. Yet, one patient suffered from an ulcerative stenosis at the gastroenterostomy after limb length alteration, which is a frequently reported complication in literature [17].

An interesting finding in this study are the differences between primary and secondary non-responders. Previous studies did not report treatment outcomes using this classification, though it is proposed as standardized terminology [6]. This study supports this classification, since it was found that only patients with 2NR were treated surgically, indicating a different treatment strategy than patients with 1NR. A note of caution is necessary as there were significant demographic differences between the two groups. Speculatively, 1NR might be a manifestation of insufficiently treated or even untreated eating behaviors and/or psychological problems, whereas 2NR might point towards anatomical problems. This theory should be further explored to prove that different treatments strategies might be applicable for the two groups of non-responders.

This retrospective study has multiple limitations that should be mentioned. Not all patients received their primary surgery in our center and therefore information about preoperative screening and treatment could 
be missed. It is questionable whether certain lifestyle and/or behavioral factors were present prior to primary surgery and if so, if the patients' adjustments met the standards used in our center. Another limitation could be the possibility that the multidisciplinary team experienced a learning curve as the multidisciplinary evaluation of non-responders was introduced in 2016 in our center. It is possible that the different members of the team experienced a change in their evaluation and treatment of non-response. Moreover, it is important to bear in mind that pharmacological therapy has not been considered in this study cohort, while it has shown beneficial results in the treatment of non-responders [18]. Finally, it should be mentioned that results regarding weight loss and complication rates are limited due to the small selected group of patients that underwent revisional surgery. Patients that failed to attend follow-up appointments (48\%) and/or investigations (19\%) similarly limited the results. An explanation for this lack of follow-up could be the patients' embarrassment.

\section{Conclusions}

This study demonstrated that the indication for revisional surgery decreased after the introduction of an MDT for assessment of non-responders after bariatric surgery. An MDT is helpful in identifying modifiable lifestyle and behavioral factors contributing to non-response. Incorporation of an MDT may contribute to the selection of patients who might benefit from revisional surgery and protect others from unnecessary surgical morbidity. Larger prospective studies are needed to evaluate the effectiveness of an MDT and might confirm that an MDT should be a mandatory part of the treatment of non-responders.

\section{List Of Abbreviations}

BMI, body mass index; BPD/DS, biliopancreatic diversion/ duodenal switch; BS, bariatric surgery; EWL, excess weight loss; MDT, multidisciplinary team; 1NR, primary non-response; 2NR, secondary nonresponse; OAGB, one anastomosis gastric bypass; RYGB, Roux-en-Y gastric bypass; SG, sleeve gastrectomy; TWL, total weight loss.

\section{Declarations}

\section{Ethics approval of consent to participate}

For this type of study formal consent was not required from all individual participants. Ethical approval has been obtained from the Medical Ethics Committee of the Máxima MC. Reference number: N19.054 (L19.065).

\section{Consent for publication}

Not applicable.

\section{Availability of data and materials}

The datasets used and/or analysed during the current study are available from the corresponding author on reasonable request. 


\section{Competing interests}

The authors declare that they have no competing interests.

\section{Funding}

Not applicable.

\section{Authors' contributions}

MR, LJ, FD and WL conceived the original study and design. MR is responsible for data collection, data recording and preparing the manuscript. MU and $\mathrm{AL}$ contributed to writing the manuscript. All authors have read and approved the final manuscript.

\section{Acknowledgements}

Not applicable.

\section{References}

1. Chang SH, Stoll CR, Song J, Varela JE, Eagon CJ, Colditz GA. The effectiveness and risks of bariatric surgery: an updated systematic review and meta-analysis, 2003-2012. JAMA Surg. 2014 Mar;149(3):275-87. doi:10.1001/jamasurg.2013.3654.

2. O'Brien PE, McPhail T, Chaston TB, Dixon JB. Systematic review of medium-term weight loss after bariatric operations. Obes Surg. 2006 Aug;16(8):1032-40.

3. Hsu LK, Benotti PN, Dwyer J, Roberts SB, Saltzman E, Shikora S, et al. Nonsurgical factors that influence the outcome of bariatric surgery: a review. Psychosom Med. 1998 May-Jun;60(3):338-46.

4. Magro DO, Geloneze B, Delfini R, Pareja BC, Callejas F, Pareja JC. Long-term weight regain after gastric bypass: a 5-year prospective study. Obes Surg. 2008 Jun;18(6):648-51. doi: 10.1007/s11695-007-9265-1.

5. van de Laar AW, Nienhuijs SW, Apers JA, van Rijswijk AS, de Zoete JP, Gadiot RP. The Dutch bariatric weight loss chart: A multicenter tool to assess weight outcome up to 7 years after sleeve gastrectomy and laparoscopic Roux-en-Y gastric bypass. Surg Obes Relat Dis. 2019 Feb;15(2):20010. doi:10.1016/j.soard.2018.11.024.

6. Bonouvrie DS, Uittenbogaart M, Luijten AAPM, van Dielen FMH, Leclercq WKG. Lack of Standard Definitions of Primary and Secondary (Non)responders After Primary Gastric Bypass and Gastric Sleeve: a Systematic Review. Obes Surg. 2019 Feb;29(2):691-7. doi:10.1007/s11695-018-3610-4.

7. Tran DD, Nwokeabia ID, Purnell S, Zafar SN, Ortega G, Hughes K, et al. Revision of Roux-En-Y Gastric Bypass for Weight Regain: a Systematic Review of Techniques and Outcomes. Obes Surg. 2016 Jul;26(7):1627-34. doi:10.1007/s11695-016-2201-5.

8. Maleckas A, Gudaityté R, Petereit R, Venclauskas L, Veličkiené D. Weight regain after gastric bypass: etiology and treatment options. Gland surgery. 2016 Nov;5(6):617-24. doi:10.21037/gs.2016.12.02.

9. Uittenbogaart M, Leclercq WK, Luijten AA, van Dielen FM. Laparoscopic Adjustable Gastric Banding After Failed Roux-En-Y Gastric Bypass. Obes Surg. 2017 Feb;27(2):381-6. doi:10.1007/s11695-016- 
2283-0.

10. Tran DD, Nwokeabia ID, Purnell S, Zafar SN, Ortega G, Hughes K, et al. Revision of Roux-En-Y Gastric Bypass for Weight Regain: a Systematic Review of Techniques and Outcomes. Obes Surg. 2016 Jul;26(7):1627-34. doi:10.1007/s11695-016-2201-5.

11. Hamdi A, Julien C, Brown P, Woods I, Hamdi A, Ortega G, et al. Midterm outcomes of revisional surgery for gastric pouch and gastrojejunal anastomotic enlargement in patients with weight regain after gastric bypass for morbid obesity. Obes Surg. 2014 Aug;24(8):1386-90. doi:10.1007/s11695014-1216-z.

12. Gastrointestinal surgery for severe obesity: National Institutes of Health Consensus Development Conference Statement. Am J Clin Nutr. 1992 Feb;55(2 Suppl):615S-619S. doi: 10.1093/ajcn/55.2.615s.

13. Pillay B, Wootten AC, Crowe H, Corcoran N, Tran B, Bowden P, et al. The impact of multidisciplinary team meetings on patient assessment, management and outcomes in oncology settings: $A$ systematic review of the literature. Cancer Treat Rev. 2016 Jan;42:56-72. doi:

10.1016/j.ctrv.2015.11.007.

14. Wright FC, De Vito C, Langer B, Hunter A; Expert Panel on Multidisciplinary Cancer Conference Standards. Multidisciplinary cancer conferences: a systematic review and development of practice standards. Eur J Cancer. 2007 Apr;43(6):1002-10.

15. Taylor C, Munro AJ, Glynne-Jones R, Griffith C, Trevatt P, Richards M, et al. Multidisciplinary team working in cancer: what is the evidence? BMJ. 2010 Mar 23;340:c951. doi: 10.1136/bmj.c951.

16. Srivastava G, Buffington C. A Specialized Medical Management Program to Address Post-operative Weight Regain in Bariatric Patients. Obes Surg. 2018 Aug;28(8):2241-6. doi:10.1007/s11695-0183141-z.

17. Palermo M, Acquafresca PA, Rogula T, Duza GE, Serra E. Late surgical complications after gastric bypass: a literature review. Arq Bras Cir Dig. 2015 Apr-Jun;28(2):139-43. doi:10.1590/S010267202015000200014.

18. Stanford FC, Alfaris N, Gomez G, Ricks ET, Shukla AP, Corey KE, et al. The utility of weight loss medications after bariatric surgery for weight regain or inadequate weight loss: A multi-center study. Surg Obes Relat Dis. 2017 Mar;13(3):491-500. doi: 10.1016/j.soard.2016.10.018.

\section{Figures}




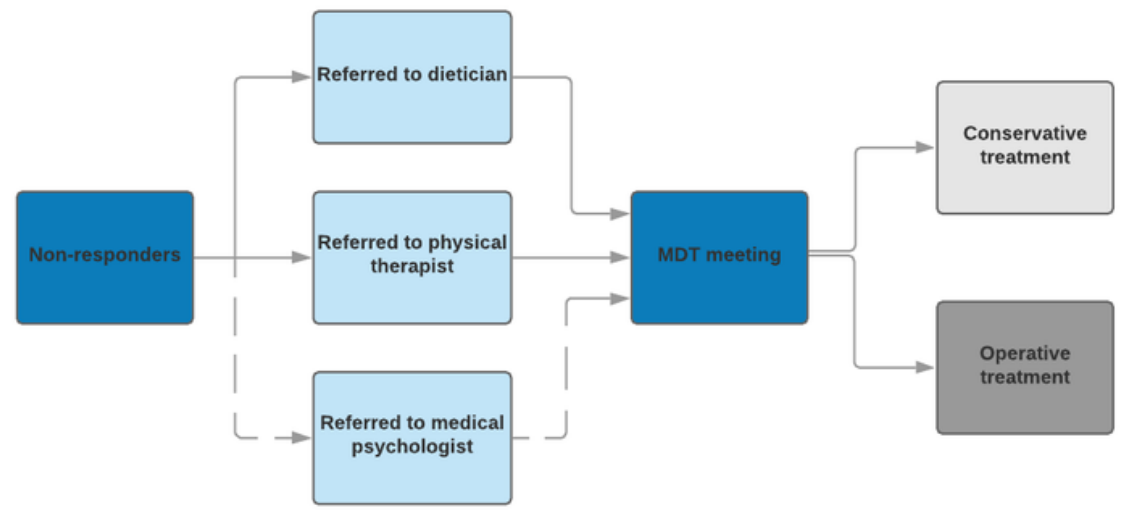

\section{Figure 1}

A caption was omitted by the authors in this version of the paper. 


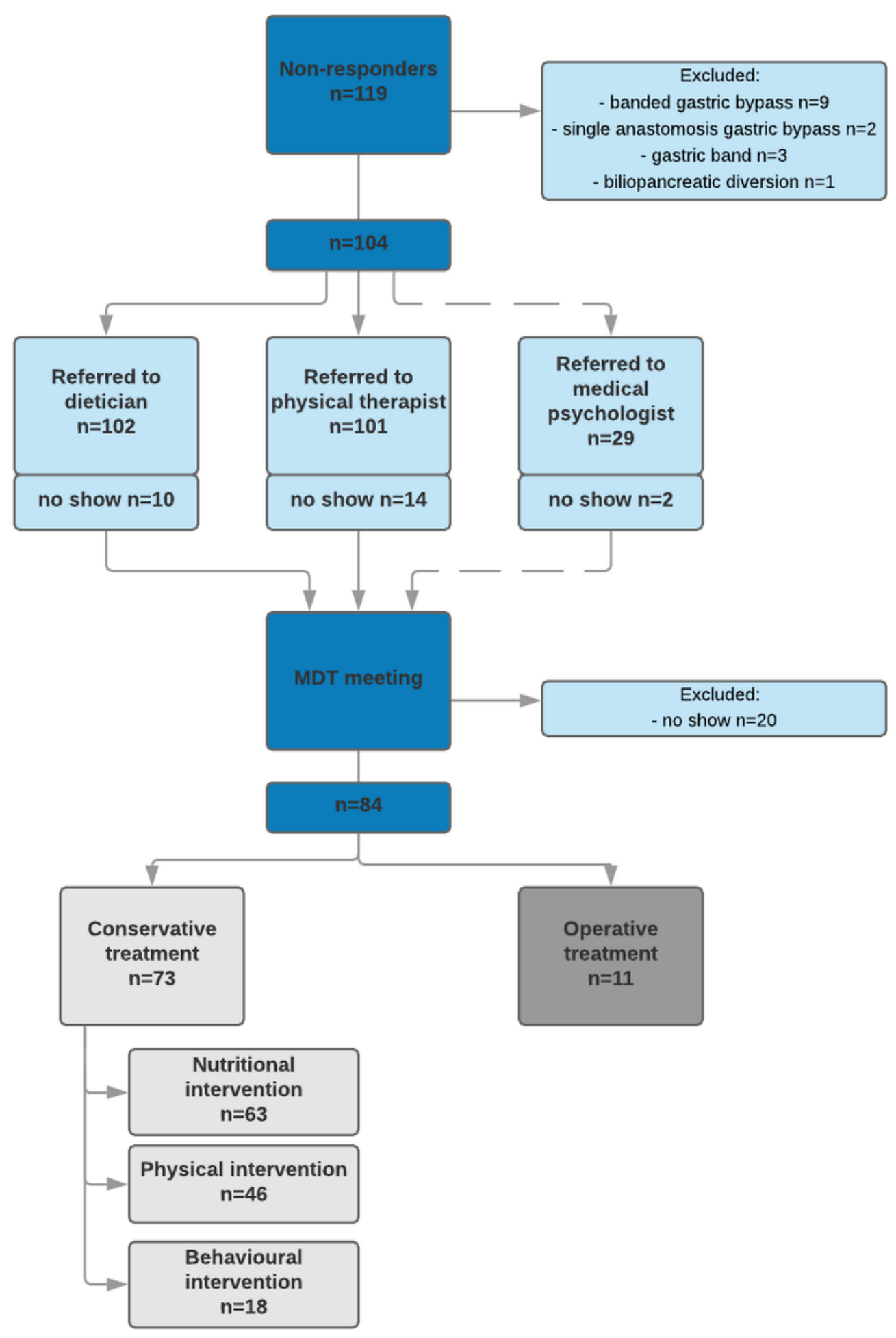

\section{Figure 2}

A caption was omitted by the authors in this version of the paper. 